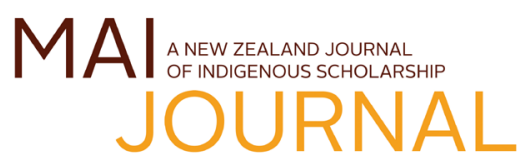

DOI: 10.20507/MAIJournal.2020.9.3.3

\title{
THE EXPERIENCES OF WHĀNAU AND KAIAKO WITH SPEECH-LANGUAGE THERAPY IN KAUPAPA MĀORI EDUCATION
}

\author{
Ellen Faithfull* \\ Karen M. Brewer ${ }^{\dagger}$ \\ Linda Hand ${ }^{\ddagger}$
}

\begin{abstract}
In New Zealand, speech-language therapists work through both the health and the education systems. In common with many Indigenous peoples, Māori have faced inequities in both health and education for decades. Kaupapa Māori education systems have been developed to support educational success and the survival of kaupapa Māori knowledge and te reo Māori. However, disparities between Māori and non-Māori still exist in the delivery of speech-language therapy services. The study reported in this article explored Māori experiences of speech-language therapy in kaupapa Māori education using Kaupapa Māori methodology, an Indigenous research approach that privileges Māori culture and knowledge. Six whānau members and educators all connected to one kōhanga reo participated in a focus group, where they reported a mix of positive and negative experiences. Thematic analysis was used to identify four significant themes. The whānau emphasised the need for te ao Māori to permeate all aspects of the therapy process, including a focus on te reo Māori, suitable settings for therapy, use of relevant resources, and appropriate methods of communication.
\end{abstract}

\section{Keywords}

speech-language therapy, Kaupapa Māori research, education, kōhanga reo

Speech-language therapy is a service intended to support children and adults with communication difficulties. Internationally there has been growing awareness that such services derive predominantly from dominant Western cultures and that non-dominant cultures tend not to be well served within this framework (Penn et al., 2017). Services that are striving to improve their effectiveness are often aware of their inadequacies but not well-equipped to overcome them. Solutions are not general and international; rather, they are particular and local. The research reported in this article aimed to provide insights into why and how services are not working in New Zealand, and what might enable services and clients to work together to improve them, to the benefit of all.

In New Zealand, speech-language therapists work through both the health and the education systems. In common with many Indigenous peoples, Māori have faced inequities in health and

\footnotetext{
Ngāpuhi. Speech-Language Therapist, Moretalk, Whāngarei, New Zealand. Email: ellen.faithfull@outlook.co.nz Whakatōhea, Ngaiterangi. Postdoctoral Research Fellow, School of Psychology, University of Auckland, Auckland, New Zealand. Senior Lecturer, School of Psychology, University of Auckland, Auckland, New Zealand.
} 
education for decades (Durie, 1998; Humpage \& Fleras, 2001; G. Smith, 1997). There are few statistics specifically on the incidence of communication difficulties in children in New Zealand, but Te Hauā Māori: Findings from the 2013 Disability Survey (Statistics New Zealand, 2015) reported that learning, speaking and intellectual difficulties occur in up to $7 \%$ of the Māori population, compared to up to $5 \%$ of the overall population of New Zealand. This is not only an example of the inequities between the populations, but also suggests a greater need for an appropriate speechlanguage therapy service for Māori. However, it is estimated that only around $4 \%$ of New Zealand speech-language therapists are Māori, not all of whom are proficient speakers of te reo (Brewer $\&$ Andrews, 2016). Most therapeutic interactions with Māori will therefore be cross-cultural and dependent on the culturally safe practices of the dominant professional culture. Cultural safety (Ramsden, 2002) is a concept developed in New Zealand that was originally applied to nursing, but over time it has developed and been applied to many clinical roles in health and disability, including speech-language therapy. The enactment of cultural safety is entirely dependent on the clinician delivering the service in a way that is determined to be safe by the consumer, not the clinician (Ramsden, 2002). In the present context, enacting cultural safety means the speech-language therapist will deliver assessment and intervention in a manner that is determined to be safe by the network of whānau, whanaunga and kaiako of each individual child.

There is little evidence concerning the quality of speech-language therapy services for tamariki Māori, or the experiences of Māori with speechlanguage therapy. A few studies have focused on Màori within the speech-language therapy literature, specifically on adults with aphasia (McLellan et al., 2011; McLellan et al., 2014). There are no known studies published on the experiences of Māori whānau regarding communication difficulties in children. The study described here therefore examined the experiences of Māori whānau, kaiako and kaiāwhina with speechlanguage therapy specifically in a kaupapa Māori education context. The aim of the research was to provide insight for speech-language therapists into how to provide a culturally safe and effective service for tamariki in kaupapa Māori education.

According to the limited research that is available, Māori are not receiving an equitable speech-language therapy service in New Zealand (Bevan-Brown et al., 2015; Macfarlane, 2000;
McLellan et al., 2014). Many speech-language therapists use standard assessments and interventions that are based on Australian, British and American norms and practices, and do not reference kaupapa Māori. Harris (2007) conducted a study whose findings questioned this approach with tamariki Māori. Standard scores in phonological awareness of bilingual tamariki Māori in both kura kaupapa Māori and mainstream schools showed poorer scores than their dominant culture counterparts. Harris analysed the nature of te reo Māori and concluded that phonological awareness is not a prerequisite for reading te reo as it is in English, and these children were reading at a higher level than their phonological awareness test results predicted. The tests, she concluded, were both linguistically and culturally inappropriate, to the detriment of tamariki Māori.

Haitana (2007) investigated the suitability of the Peabody Picture Vocabulary Test (PPVT-III) for tamariki Māori aged 5-10 years. She concluded that the PPVT-III had some bias, but overall was suitable for use with tamariki Māori. However, she also concluded that the standard way of using this assessment was often inappropriate for tamariki Māori. Her recommended adjustments included "utilising a more dynamic assessment approach, and prioritising Māori beliefs, values, and experiences throughout test administration" (Haitana, 2007, p. 135). Gallagher (2008) had similar findings when examining the effectiveness of culturally responsive and pedagogically appropriate language intervention in Māori immersion settings. The findings indicated that including children with language difficulties in a class programme was more appropriate than isolating them (Gallagher, 2008).

Work with Indigenous Australian children also highlights the inherent problem of identifying communication differences and deficits in crosscultural speech-language therapy. Gould (2008) developed culturally safe assessments that incorporated elements of the communication system used by the Aboriginal community she was working in. The children performed far better in the culturally appropriate assessments than they had in the dominant culture assessments, highlighting the impact cultural and linguistic differences can have on assessment.

Adaptations for kaupapa Māori education settings involve considerably more than finding appropriate assessment tools. In her autoethnography, Hitaua (2013) highlighted how the relationship between speech-language therapist and the child, whānau and community is critical. 
Hitaua indicated that an effective speech-language therapist in these settings should be competent in te reo and tikanga Māori. Any intervention cannot proceed effectively without the therapist first putting time into whakawhanaungatanga, building the relationship with the whānau and kaiako. The voices of the whānau should be foregrounded, visibly valued and respected (Hitaua, 2013).

This is echoed in an Indigenous Canadian context. Ball and Lewis (2014) interviewed First Nations elders, grandparents and parents about their views on their children's speech and language learning, the value of early learning and intervention programmes, and goals for speech-language therapy. Participants reported that the priority was developing the skills of First Nations people to provide culturally appropriate speech-language therapy to their children. However, nearly $80 \%$ of participants also believed that a non-First Nations speech-language therapist could support First Nations children as long as they were willing to learn about First Nations' culture and perspectives on communication development.

Research by McLellan et al. (2014) aimed to ascertain what makes speech-language therapy services culturally safe, competent and accessible to Māori adults with aphasia. The therapeutic relationship between the speech-language therapist, the person with aphasia and their whānau was demonstrated to be central to the success of therapy. It was influenced directly by the setting, resources used in therapy, and the recognition of the Māori worldview throughout the therapy process (McLellan et al., 2014). This research highlights a need for the understanding and incorporation of te ao Māori in speech-language therapy practice with Māori. There is currently a lack of guidance for speech-language therapists in New Zealand as to how to implement this in practice (McLellan et al., 2014).

Relevant to this discussion is the Treaty of Waitangi, entered into by the Crown and Māori in 1840 (Orange, 2011). The three articles of the Treaty have contemporary implications for health and education in New Zealand, and therefore speech-language therapy. The modern implications of Articles 2 and 3 of the Treaty clearly state that Māori should be able to determine what will benefit them, and that they should receive a fair share of services (Durie, 1998). This includes the right to education and specialist services in te reo Māori, delivered in a manner equally determined by the whānau and the speech-language therapist. Alongside these articles, many Treaty principles have been established by institutions such as the Waitangi Tribunal and the Court of Appeal (Durie, 1998). The principles most commonly used in policy documents and regularly applied in speech-language therapy are participation, protection, and partnership (Tomlins-Jahnke \& Te Rina Warren, 2011). In this context, the Treaty principles participation, protection, and partnership imply that Māori will participate as Māori in assessment and intervention, that te reo Māori will be protected, and that the whānau have an equal role in decision making for their tamariki.

The study reported here explored the speechlanguage therapy experiences of whānau and kaiako in kaupapa Māori education. Significant factors in whānau-clinician interactions and therapy outcomes are discussed. The aim of this work was to advance the knowledge and inform the practice of speech-language therapists, and ultimately improve the quality of the speech-language therapy service provided to tamariki in kaupapa Māori education.

\section{Method}

This is a Kaupapa Māori research study. Kaupapa Māori research is an Indigenous research approach that includes addressing the power imbalance between Māori and Pākehā (Bishop, 1999; Pihama, 2010; G. Smith, 1997; L. Smith, 1999; Walker et al., 2006), emphasising the validity of te ao Māori as a worldview, and ultimately benefiting Māori (G. Smith, 2012). It is conducted by Māori, for Māori, and with Māori (L. Smith, 1999). A crucial aspect of Kaupapa Māori research is whakawhanaungatanga, which legitimises whānau leadership in the research and questions the importance of researcher-participant distance, which is so grounded in mainstream research practice (Bishop, 1996; Mead, 2003; L. Smith, 1999; Wihongi, 2002).

\section{Participants}

This research involved six participants who were recruited through the researchers' personal networks. They were all connected to one kōhanga reo and the adjoining primary school in a large urban area. Two participants were māmā of kōhanga tamariki who had received or were receiving speech-language therapy. One was a kaimahi at the kōhanga reo and also had a child suspected of needing speech-language therapy but who had not yet been referred. One was a kaiāwhina at the primary school and had a niece and nephew who attended the kōhanga reo and were receiving speech-language therapy. Two were kaiako, one 
from the kōhanga reo and one from the Māori immersion unit in the local primary school.

\section{Procedure}

The research was approved by the University of Auckland Human Participants Ethics Committee (approval number 013511). Initial contact began through whakawhanaungatanga when the researchers were approached by Māmā A, the mother of a kōhanga tamaiti who wanted to share her experience of speech-language therapy. Māmā A liaised with the kōhanga reo whānau at a hui, where they discussed the proposed research. The researchers attended two separate hui, where they provided verbal and written information about the research, and answered questions from the whānau. The whānau chose to participate as a group rather than separately and took it upon themselves to invite the kaiako and kaiāwhina from the primary school to join them. The kōhanga reo whānau were offered a return visit by the first author to discuss the emerging analysis. This hui was attended by whānau and kaiako from the kōhanga reo where the research was held, as well as kaiako from other kōhanga reo in the region.

\section{Data collection}

Data collection took place during a hui with the first and second authors, held at the kōhanga reo. Tikanga Māori was followed, including beginning and ending with a karakia and sharing kai afterwards. Each participant gave their mihi and described their connection to the research through their relationship with tamariki affected by speech and language difficulties. The participants were then invited to kōrero about their experience with speech-language therapy. The researchers asked questions for clarification, and to ensure that all relevant areas were explored. The kōrero was predominantly in English, although participants often used Māori words and phrases. The hui was audio recorded, with the consent of all participants.

\section{Data analysis}

The first author transcribed, read and coded the transcript of the hui using NVivo qualitative data analysis software (QSR International, 2012). A pseudonym was assigned to each participant using their role (Māmā, Kaiako or Kaiāwhina) and the initial letter of their first name. Thematic analysis (Braun \& Clarke, 2012) was employed as a method of data analysis. Thematic analysis allows the researcher to identify and make sense of commonalities in a group of shared experiences (Braun \& Clarke, 2012). Individual quotes were coded and grouped into themes based on common patterns. As analysis progressed, relationships between the themes emerged. The coding, themes and the relationships between them were discussed in detail within the research team. During the follow-up hui the whannau responded positively to the analysis and identified their experiences in the themes. They also provided advice for the dissemination of the research.

\section{Findings}

Analysis of the data gathered during the focus group identified four significant themes, which are represented diagrammatically in Figure 1 and discussed individually below.

\section{It's difficult to get into the system}

Whānau felt that they had faced difficulties engaging in speech-language therapy services from the outset: "It's just getting into the system for us that's the biggest challenge"(Māmā B). Whānau reported that the Ministry of Education (2014)

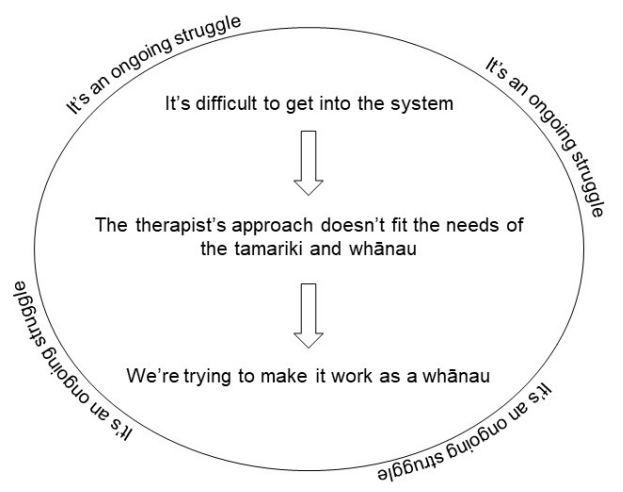

FIGURE 1 Themes 
eligibility criteria for speech-language therapy are a barrier to accessing services, with no perceived support for tamariki who are ineligible (at the time of writing the criteria for eligibility have been removed). Māmā B had referred both her tamariki to the Ministry of Education for speech difficulties but was told they did not meet the criteria. She therefore had to seek an alternative service, which she described as "a big struggle". She took both tamariki to a local university clinic, where they had a positive experience with student speech-language therapists. As illustrated in the following exchange, some of the whānau were not aware of the process of referral and assessment for eligibility. Kaiako P asked, "So that 2\% [of eligible tamariki]—what happens to the rest of them? Do you still be involved?" Māmā B replied, "You're on your own; you have to go out and find it."

Advocacy, for themselves and for others, was a large part of whānau efforts to access public services. Whānau described how persistent they had to be during the referral process to ensure their concerns were acknowledged. Māmā B expressed how hard she found it to be constantly advocating for her tamariki, saying, "It's just hard, I just don't like the whole thing. You just push, push, push all the time." She and Māmā A described going separately to the school principal to ask for support in advocating for their tamariki, only to receive no support at all. Māmā B realised that she was "not going to get any help here".

Māmā A acknowledged that the most vulnerable whānau and tamariki were unlikely to be able to advocate for themselves in the same way she had for her tamaiti: "Who's not getting treatment for their tamaiti because I'm pushing for mine?" She and Māmā B recognised that they were more privileged than some whānau, which meant their tamariki were more likely to have access to public or private speech-language therapy services. The whānau who are most in need often lack the resources to advocate for public services or to access private speech-language therapy, and are at risk of more adverse outcomes in the long term. Māmā B acknowledged that "there'll be a lot of whānau that just can't afford [therapy] privately".

Whānau who were eligible for services expressed concern about the amount of support they received from the speech-language therapist. This was mostly centred on the frequency of the service. They discussed the self-doubt they felt when they tried to be proactive with the tamariki and were not sure if they were implementing the therapy tasks correctly: "It was hard ... 'cause [the speech-language therapist] doesn't see [my tamaiti] for such a long time, you're thinking am I actually doing this right?" (Māmā A). Whānau also described feeling unsupported when they were given information about the communication skills of the tamariki. Māmā A said:

You know they give a summary, she sent us that report ... It was really, like, clinical, I mean you know I'm not exactly ignorant, and I didn't know what a lot of the terms meant, and they weren't explained to us . . . It would have been nice for someone to actually sit down and go through the report and say in lay terms this is what [my tamaiti] does.

\section{The therapist's approach doesn't fit the needs of the tamariki and whānau}

A common issue raised by the whānau was the lack of focus on te reo Māori and te ao Māori in the therapist's approach. Kaiako $M$ described this as a "focus on English and not the way he's actually going". Whānau unanimously agreed that the incorporation of te reo Māori in speechlanguage therapy assessment and intervention was fundamental. Māmā A described her concern that the speech-language therapist was not seeing a complete picture of her tamaiti and his communication. The speech-language therapist was basing all her clinical reasoning on assessment of his skills in English, while Māmā A and his kaiako believed te reo Māori was his stronger language:

It does worry me that she sees these little glimpses of him when she talks to him in English . . . so that's what she captures and that's what she evaluates... Then how well do you actually know his competency, and then how well are these interventions designed if you don't have a measure for it?

Kaiāwhina $\mathrm{H}$ described a situation where the speech-language therapist observed her and the tamaiti interacting in te reo Māori and was surprised that his communication skills were better than expected. These experiences highlight a challenging aspect of monolingual speech-language therapists working with bilingual tamariki. If the speech-language therapist is unable to accurately assess the tamaiti in all languages, then the validity of intervention is questionable. Kaiāwhina $\mathrm{H}$ also described feeling "backed up against a wall" during a goal-setting meeting at which she was the only te reo Māori speaker present:

In the end I had to like tell her before I exploded, you know 'cause just out of frustration ... because she was trying to tell me that he doesn't talk ... or 
he'll talk one word, and I said, "Well no, he talks to me in sentences," and she said, "Well I'm not seeing it" . . . and I said to her, "Well you have to realise that te reo Māori is his stronger language."

The lack of attention paid by this speech-language therapist to the te reo Māori skills of the tamariki demonstrates a lack of cultural safety. Whānau felt that the service was often delivered based on what the speech-language therapist wanted, rather than what the whānau needed. Māmā A commented on how long it took her to convince the speechlanguage therapist to visit the kōhanga reo:

[The speech-language therapist] kept approaching me and saying, "I'll come to your house and evaluate him," and it was like but actually now most of his time's at kōhanga in immersion, and I think it's important that it needs to be incorporated into the interventions and assessments, and she was very hesitant.

The whānau felt that te ao Māori should permeate all aspects of the therapy process, including a focus on te reo Māori, suitable settings for therapy, use of relevant resources, and appropriate methods of communication. These factors contributed directly to the relationship between the whannau and the speech-language therapist, and to the safety and success of the intervention. It is well established that building positive relationships and the recognition of te ao Māori is an essential aspect of Māori educational achievement (Bishop, 1999; G. Smith, 1997). Recognition of the Māori worldview has also been shown to be a crucial aspect of developing positive therapeutic relationships and contributes significantly to the success of therapy (McLellan et al., 2014). The desire for incorporation of culture by speech-language therapists in their practice with their children was also reported by First Nations people in Canada (Ball \& Lewis, 2014). As noted above, Gould (2008) found that adapting speechlanguage therapy assessments to be culturally appropriate to Australian Aboriginal children had a positive impact on their performance.

When the speech-language therapist did visit the kōhanga reo, Māmā A and Kaiako P felt that the experience had been positive and that all involved now better understood each other's perspective. However, following this visit, the speech-language therapist continued to focus on English. The speech-language therapist still did not fully engage with the kōhanga reo until Māmā A wrote a letter of complaint to the Ministry of Education:
It took about a year of me pushing and getting, I guess, confident enough to push back and say actually this is my child, my choice ... You know, you've got an obligation under the Treaty to do this, and then I wrote a letter of complaint to the Ministry and said that actually they're creating inequities for our babies by not doing this ... and then I got a phone call from [the speech-language therapist] after that, saying that she would work with kōhanga.

This situation is an example of the extent to which whānau have to go to advocate for their tamariki to receive equitable support. The whānau unanimously agreed that we do not currently have a system that "supports or facilitates speechlanguage therapy . . . not only within an immersion context for the reo but also within the te ao Māori context" (Māmā A). The whānau all emphasised an overwhelming need for speech-language therapists who speak te reo Māori. While the speech-language therapist had been helping the tamariki "up to a point", there was a crucial aspect of the service missing. The need for te reo speakers was highlighted in every aspect of speech-language therapy service delivery, from the identification of speech and language issues to assessment and intervention. Māmā A and Kaiako P described their uncertainty about the skills of the tamaiti in te reo Māori: "We were picking up that actually there were probably little differences ... Maybe there were less issues with his reo, but we're not qualified to make that [call], and we didn't have anyone to tell us."

When Māmā A wrote the letter of complaint to the Ministry of Education regarding the lack of recognition of te reo Māori, it responded by acknowledging the needs of the whānau but reported a current "lack of capacity" to address them (Ministry of Education, 2014). This response is of concern and acknowledges the challenge of providing equitable services, as indicated in their information (Ministry of Education, 2014). It appears that eligibility does not necessarily equal access. The kōrero from this research indicates that the model of service participants received does not support speech-language therapy for tamariki as Māori, and that there is a lack of Māori therapists or therapists proficient in tikanga Māori and te reo Māori.

Māmā A's experience is in contrast with Māmā B's positive experience with speech-language therapy at a university clinic. The therapists performed their service in a culturally safe way, taking into account the priorities of the whānau, 
which led to successful therapy outcomes for both tamariki:

They were really awesome at [the university clinic], like they'd do things in te reo and games in te reo ... so they really tried to understand him ... I could be just assuming but I thought they were just Pākehā and tauiwi. Honestly I didn't really ask if they were Māori or anything like that, but they understood that that's what [my tamaiti] was doing in full immersion.

This experience demonstrates that the inclusion of te reo Māori in therapy, even by non-Māori therapists, can lead to more positive therapy outcomes for tamariki and whānau. However, the whānau recognised that "it's not just the language", and that an understanding of te ao Māori is also important. Māmā A and Kaiāwhina H described a situation during assessment where the speechlanguage therapist asked whether the tamaiti could rhyme. Rhyming is a milestone of speech and language development in English-speaking children and is regularly incorporated into the mainstream education curriculum. In the kaupapa Māori context, this milestone is irrelevant because rhyming is not an important concept in te ao Māori. The speech-language therapist's lack of awareness of this incongruence could lead to misdiagnosis of communication delays or disorders. The whānau also discussed how understanding the context of communication is greatly influenced by culture. The speech-language therapist may not be able to understand richness of knowledge and language skills if they do not understand the context of the communication.

The whānau believed that understanding te ao Māori for speech-language therapy requires understanding not only possible differences in communication development but also the attitudes of Māori whānau about the difficulties their tamariki are experiencing. Kaiako $P$ felt her perspective on the tamariki who had communication difficulties differed from that of the speech-language therapist. The therapist was impairment focused, whereas Kaiako P saw each tamaiti as a whole person. As long as she could understand what they were communicating, it did not matter to her if they used perfect speech and language: "OK, you have the speech but it's . . . their eyes, their whole body language you know, and you get [what they're saying] so ka pai, and if they're happy I'm happy."

The perspective of the whannau on building relationships also appeared to differ from that of the speech-language therapist. The whānau all agreed that building a real relationship with the tamariki was a fundamental aspect of the therapy process, with Kaiako P commenting:

Whakarata te tamaiti. I think that's, you know, very important to make progress anyhow ... I mean it's challenging at times but you know ... you can't really kinda go anywhere further if you don't have that to start with.

In Māmā B's positive experience with speechlanguage therapy, the therapists had made an effort to get to know the tamariki and incorporate their interests into therapy, as well as te reo Māori. In the negative experiences of speech-language therapy, the whānau described poor therapeutic relationships between the tamariki and therapist. Kaiāwhina $\mathrm{H}$ described feeling she had to give [tamaiti] a "warning" that the speech-language therapist was coming to see him at school; "otherwise he'd probably just run away".

\section{We're trying make it work as a whānau}

Despite the difficulties the whannau faced regarding the therapist's approach, they did what they could to facilitate the speech-language therapist and the therapy process. They recognised that the speech-language therapist may find it challenging to come into an unfamiliar environment. Māmā A described being unsure at first why the speech-language therapist would not come to the kōhanga, so sought advice from a kuia: "It was [kuia] who put me straight she's like look at it from her point of view she's not Māori it could be scary you've gotta awhi her through it and make her feel welcome."

The kōhanga reo tried to make the speechlanguage therapist feel comfortable in their environment. Māmā A described how Kaiako $P$ made an effort to include the speech-language therapist in the kōhanga activities even though she did not speak te reo Māori: "We invited her in and [Kaiako P] was awesome, you know, [she] really walked her through ... allowed her to give karakia in English. I remember [her] saying it doesn't matter how you pray, God understands all languages."

This effort made by the whānau shows how much they valued the speech-language therapist and her input into the tamariki. The whannau also tried to do what they could to adapt the therapy process based on English into te reo Māori, and make it appropriate for the kaupapa Māori environment. Kaiako $\mathrm{M}$ described a typical interaction between her, the tamariki and the therapist: 
She comes in four times a year, ay, she comes in, and she'll video record you, and then you've gotta translate it all [laughs]. She's like, "What's happening here? What's engaging here?" "Well this is what happened, this is what he said, I've said this ..."

Kaiako P described constantly translating the activities she was given and doing them one on one with tamaiti as "quite challenging". Both she and Kaiako M implemented the interventions given to them by the speech-language therapist in a way they found more appropriate for their environment. Māmā A described how Kaiako P adapted the programme for her tamaiti so that it could be done with all the tamariki:

With [my tamaiti] the rauemi was supposed to be one on one ... but [Kaiako P] didn't wanna pull him apart from the rest of the class, so [she was] doing it with the whole rōpū, ay, with all the tuākana, and I think they all benefited from that, and [my tamaiti] doesn't feel stink, like, oh I've gotta go be pulled aside.

Similarly, Kaiako $M$ found the tamariki benefited more by completing their therapy as part of a group: "[S]o then . . . they're not there on their own and, like, 'Oh why am I the only one." These experiences exemplify the amount of effort and thought the kaiako and kaimahi had to put into the delivery of prescribed interventions to make them relevant to the tamariki, firstly by translating all the tools into te reo Māori and secondly, and perhaps more crucially, by adapting the tools so that they fit into te ao Māori.

The whānau exhibited a collective vision of the success of the tamariki throughout the hui. Māmā A described how supportive the kōhanga reo had been of her whānau:

When I'd approached [the kōhanga reo] one of the first things I said was [my tamaiti has] got speech impediments and just the aroha I had and tautoko from [kaiako and kaimahi], they actually sat down in a hui like this even before like I put words on paper just to see how they could ... awhi us as a whānau, and then they invited [the speech-language therapist] to come and speak to them.

The mothers in the group emphasised how important the input of the kaiako was in the identification and treatment of communication difficulties. Throughout the hui whānau consistently referred to the kohanga reo kaiako for her opinion on the tamariki. Māmā A said:
I take Kaiako P's opinion way over, sorry, [the speech-language therapist's] or other, just because [she's] had the experience. [Kaiako P] know[s] the tamariki, [she] can pinpoint what they can and can't say .... and I do that with Kaiāwhina $\mathrm{H}$ as well, you know, because she's seen more of [my tamaiti] ... in different contexts than I do, and I'm reliant on that.

\section{It's an ongoing struggle}

There is a clear overlapping of experiences between the first three themes, which is summed up by the fourth: It's an ongoing struggle. This overarching theme reflects the whānau's desire to have speechlanguage therapy input into the development of their tamariki, and their motivation to see their tamariki succeed. No matter how privileged a whānau is and how many resources they have, they still receive an inequitable service. The whānau work together to support the tamariki and try to accommodate the speech-language therapist as best they can. However, underlying differences in values and approaches, and the therapist's lack of knowledge of te reo Māori continue to create barriers.

In the other themes, the whānau described difficulty accessing both public mainstream services and services appropriate to kaupapa Māori education. They had to adapt mainstream services to suit their needs, which were not always addressed by the speech-language therapist. Ultimately, they agreed that there is a distinct absence of systemic support for speech-language therapy in kaupapa Māori education contexts.

\section{Clinical implications}

The voices of these whānau send a powerful message about what is important and what does not work. The challenges encountered by the whānau throughout their journey at both the surface and the systemic levels should not be insurmountable. Surface-level solutions include the recruitment of more Māori into speech-language therapy training, upskilling non-Māori therapists, and development of kaupapa Māori resources. Increasing the number of Māori therapists alone, while important, will not fully address disparities in specialised services. It is the responsibility of all health and education professionals to be aware of the role they may play in creating, maintaining or potentially eliminating Māori disparities through culturally safe practice (Curtis et al., 2014). The whānau at the follow-up hui emphasised the importance of the speech-language therapist having respect for the knowledge of the kaiako. Their knowledge 
alone is an extremely valuable resource for speechlanguage therapists. Kaiako at the follow-up hui suggested that professional development for speech-language therapists would aid in their understanding of communication development and difficulties. This would prepare them better to identify tamariki with communication problems, and to collaborate in intervention.

\section{Conclusion}

Whānau who choose kaupapa Māori education for their tamariki should have access to equitable support for their communication needs. Culturally safe speech-language therapy for tamariki in kaupapa Māori education is grounded in te ao Māori and te reo Māori as inherent aspects of intervention. A collaborative approach between therapist, whānau and kaiako based on mutual respect is most likely to lead to positive therapeutic relationships and therapy outcomes for the tamariki.

\section{Acknowledgements}

Ngā mihi nui ki te whānau o te kōhanga reo me rūmaki reo mo tō koutou kōrero. I am profoundly grateful to the whānau, kaiako and kaiāwhina who so generously gave their time to share their experiences. To Māmā A, for all her extra energy spent organising hui and liaising with the kōhanga reo. To the wider whānau, kaiako and kaimahi for their input into the findings and future directions. To Karen and Linda, for their endless awhi and time. And to Barney and my whānau, for getting me to this place.

$\begin{array}{ll}\begin{array}{ll}\text { Glossary } \\ \text { aroha }\end{array} & \text { love } \\ \text { awhi } & \text { embrace } \\ \text { hui } & \text { meeting } \\ \text { kai } & \text { food } \\ \text { kaiako } & \text { teacher } \\ \text { kaiāwhina } & \text { helper/teacher aide } \\ \text { ka pai } & \text { good } \\ \text { kaimahi } & \text { worker, staff } \\ \text { karakia } & \text { prayer } \\ \text { kaupapa Māori } & \text { research by Māori, with } \\ & \text { Māori, for Māori; a } \\ & \text { term used to describe } \\ & \text { traditional Māori ways } \\ \text { of doing, being and } \\ \text { thinking, encapsulated in } \\ \text { a Māori worldview } \\ \text { Māori immersion preschool } \\ \text { child who attends kōhanga } \\ \text { reo }\end{array}$

$\begin{array}{ll}\begin{array}{l}\text { kōrero } \\ \text { kuia } \\ \text { kura kaupapa }\end{array} & \begin{array}{l}\text { talk } \\ \text { female elder } \\ \text { school immersion primary } \\ \text { māmā }\end{array} \\ \text { Māori } & \begin{array}{l}\text { Indigenous peoples of New } \\ \text { Zealand }\end{array} \\ \text { mihi } & \text { speech of greeting } \\ \text { Pākehā } & \text { New Zealander of } \\ & \text { European descent } \\ \text { rauemi } & \text { resource } \\ \text { rōpū } & \text { group } \\ \text { tamaiti } & \text { child } \\ \text { tamariki } & \text { children } \\ \text { tauiwi } & \text { non-Māori } \\ \text { tautoko } & \text { support } \\ \text { te ao Māori } & \text { the Māori world } \\ \text { te reo Māori } & \text { the Māori language } \\ \text { tikanga Māori } & \text { customary values and } \\ \text { practices } & \text { older children } \\ \text { tuākana } & \text { settle/tame/subdue } \\ \text { whakarata } & \text { process of establishing } \\ \text { whakawhanaungatanga } & \text { well to others } \\ \text { family } & \text { relatives, relations } \\ \text { whānau } & \\ \text { whanaunga } & \end{array}$

\section{References}

Ball, J., \& Lewis, M. (2014). First nations elders' and parents' views on supporting their children's language development. Canadian Journal of Speech-Language Pathology and Audiology, 38(2), 224-237.

Bevan-Brown, J., Berryman, M., Macfarlane, S., Hickey, H., Smiler, K., \& Walker, T. (2015). Working with Māori children with special education needs: $\mathrm{Hi}$ mahi whakahirahira. NZCER Press.

Bishop, R. (1996). Collaborative research stories: Whakawhanaungatanga. Dunmore Press.

Bishop, R. (1999). Kaupapa Maori research: An indigenous approach to creating knowledge. In N. Robertson (Ed.), Māori and psychology: Research and practice. Proceedings of a symposium sponsored by the Maori and Psychology Research Unit, Department of Psychology, University of Waikato, Hamilton, Thursday 26th August 1999 (pp. 1-6). Māori and Psychology Research Unit, University of Waikato.

Braun, V., \& Clarke, V. (2012). Thematic analysis. In H. Cooper (Ed.), APA handbook of research methods in psychology (Vol. 2, pp. 57-71). American Psychological Association. https://doi.org/gf8893

Brewer, K., \& Andrews, W. (2016). Foundations of equitable speech-language therapy for all: The Treaty of Waitangi and Māori health. Speech, 
Language and Hearing, 19(2), 87-95. https://doi. org/fbpw

Curtis, E., Rei, P., \& Jones, R. (2014). Decolonising the academy: The process of re-presenting indigenous health tertiary teaching and learning. Diversity in Higher Education, 15, 147-165. https://doi.org/ bd6j

Durie, M. (1998). Whaiora: Māori health development. Oxford University Press.

Gallagher, K. L. (2008). An intervention approach to target vocabulary development in te reo Maori in Maori immersion settings [Master's thesis, University of Canterbury]. UC Research Repository. https://ir.canterbury.ac.nz/handle/10092/1879

Gould, J. (2008). Non-standard assessment practices in the evaluation of communication in Australian Aboriginal children. Clinical Linguistics \& Phonetics, 22(8), 643-657. https://doi.org/b3g2g7

Haitana, T. (2007). Testing tamariki: How suitable is the PPVT-II? [Master's thesis, University of Canterbury]. UC Research Repository. https:// ir.canterbury.ac.nz/handle/10092/1399

Harris, F. (2007). (Re-)constructing Māori children as achieving learners [Doctoral thesis, University of Canterbury]. https://ir.canterbury.ac.nz/bitstream/ handle/10092/1062/thesis_fulltext.pdf?se

Hitaua, N. (2013). Speech language therapy in Maori immersion settings: An autoethnography [Unpublished manuscript]. University of Auckland.

Humpage, L., \& Fleras, A. (2001). Intersecting discourses: Closing the gaps, social justice and the Treaty of Waitangi. Social Policy Journal of New Zealand, 16, 37-54.

Macfarlane, A. (2000). The value of Māori ecologies in special education. In D. Fraser, R. Moltzen, \& K. Ryba (Eds.), Special education in Aotearoa New Zealand (pp. 77-98). Dunmore Press.

McLellan, K., McCann, C., \& Worrall, L. (2011). Māori with aphasia: A people without a voice? New Zealand Medical Journal, 124(1330), 48-57.

McLellan, K., McCann, C., Worrall, L., \& Harwood, M. (2014). Māori experiences of aphasia therapy: "But I'm from Hauiti and we've got shags.” International Journal of Speech Language Pathology, 16(5), 529-540. https://doi.org/fbpx

Mead, H. M. (2003). Tikanga Māori: Living by Māori values. Huia.

Ministry of Education. (2014, September). The communication service. https://www.education.govt.nz/ assets/Documents/School/Supporting-students/ Students-with-Special-Needs/Communication ServiceSEP2014.pdf
Orange, C. (2011). The Treaty of Waitangi. Bridget Williams Books. https://doi.org/7gx

Penn, C., Armstrong, E., Brewer, K., Purves, B., McAllister, M., Hersh, D., Godecke, E., Ciccone, N., \& Lewis, A. (2017). Decolonizing speech-language pathology practice in acquired neurogenic disorders. Perspectives of the ASHA Special Interest Groups, 2(2), 91-99. https://doi.org/fbpz

Pihama, L. (2010). Kaupapa Māori theory: Transforming theory in Aotearoa. He Pukenga Kōrero, 9(2), $5-14$.

QSR International. (2012). NVivo (Version 10) [Computer software].https://www.qsrinternational. com/nvivo-qualitative-data-analysis-software/ home

Ramsden, I. (2002). Cultural safety and nursing education in Aotearoa and Te Waipounamu [Doctoral thesis, Victoria University of Wellington]. https:// croakey.org/wp-content/uploads/2017/08/ RAMSDEN-I-Cultural-Safety_Full.pdf

Smith, G. (1997). The development of Kaupapa Maori: Theory and praxis [Doctoral thesis, University of Auckland]. ResearchSpace. https://researchspace. auckland.ac.nz/handle/2292/623

Smith, G. (2012). Kaupapa Māori: The dangers of domestication. New Zealand Journal of Educational Studies, 47(2), 10-22.

Smith, L. (1999). Decolonizing methodologies: Research and Indigenous people. University of Otago Press.

Statistics New Zealand. (2015). Te hauā Māori: Findings from the 2013 Disability Survey. http://archive. stats.govt.nz/browse_for_stats/health/disabilities/ He-haua-maori-findings-from-2013-disabilitysurvey.aspx\#gsc.tab=0

Tomlins-Jahnke, H., \& Te Rina Warren, K. (2011). Full, exclusive and undisturbed possession: Maori education and the Treaty. In V. Tawhai \& K. Gray-Sharp (Eds.), Always speaking: The Treaty of Waitangi and public policy (pp. 43-62). Huia.

Walker, S., Eketone, A., \& Gibbs, A. (2006). An exploration of Kaupapa Māori research, its principles, processes and applications. International Journal of Social Research Methodology, 9(4), 331-344. https://doi.org/bx82s2

Wihongi, H. (2002, November 27-29). The process of whakawhanaungatanga in Kaupapa Māori research [Paper presentation]. 6th Australia and New Zealand Third Sector Research Conference, Auckland, New Zealand. 